\title{
Correction to: Grinding burn on hardened steel: characterization of onset mechanisms by design of experiments
}

\author{
F. Del $\operatorname{Re}^{1} \cdot$ M. Dix ${ }^{2} \cdot$ F. Tagliaferri ${ }^{3}$ (D)
}

Published online: 17 May 2019

(C) Springer-Verlag London Ltd., part of Springer Nature 2019

\section{Correction to: The International Journal of Advanced Manufacturing Technology https://doi.org/10.1007/s00170-018-3156-6}

Regrettably, before online publication, the image of Fig. 8 has been pasted twice as Fig. 7.

The correct image is shown below.

Publisher's note Springer Nature remains neutral with regard to jurisdictional claims in published maps and institutional affiliations.

The online version of the original article can be found at https://doi.org/ 10.1007/s00170-018-3156-6

\section{F. Tagliaferri}

flaviana.tagliaferri@unicusano.it

1 Department of Industrial Engineering, University of Naples Federico II, Piazzale Vincenzo Tecchio, 80 Naples, Italy

2 Institute for Machine Tools and Production Processes (IWP),

Technische Universit”at Chemnitz, Reichenhainer Str,

70 Chemnitz, Germany

3 University Niccol’o Cusano, Via Don Carlo Gnocchi 3, Rome, Italy 
Fig. 7. Main effects plots for Fx: a full quadratic regression model; $\mathrm{b}$ reduced regression model

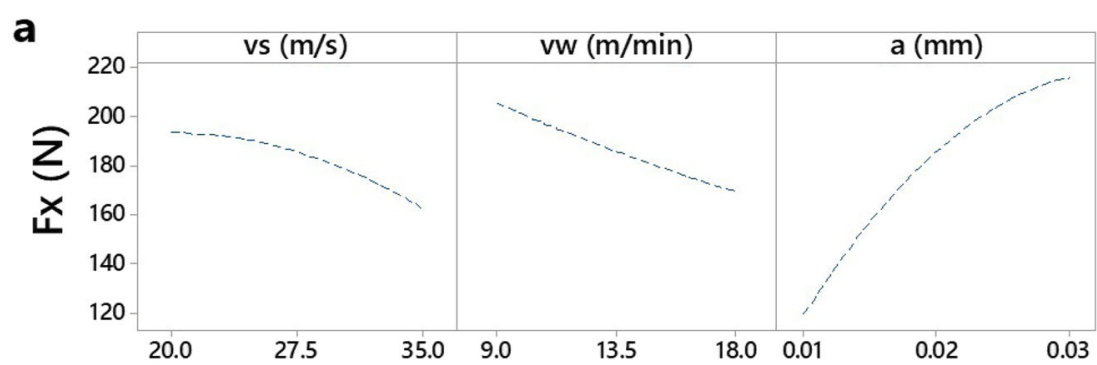

b

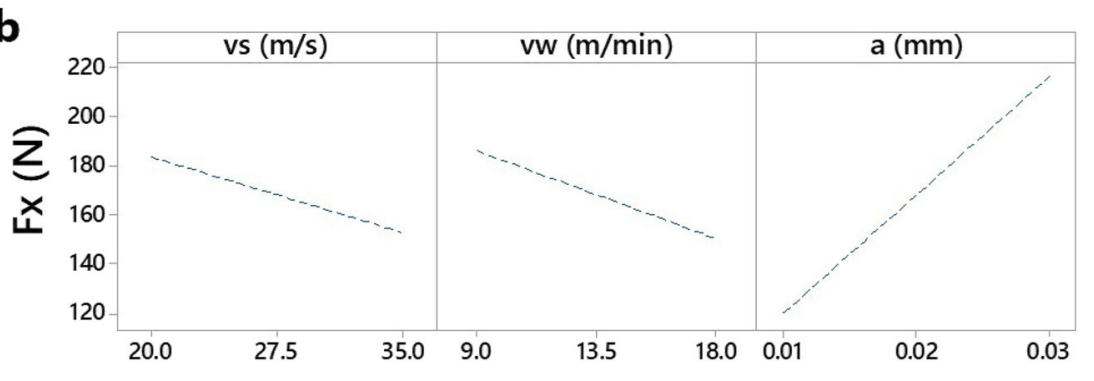

